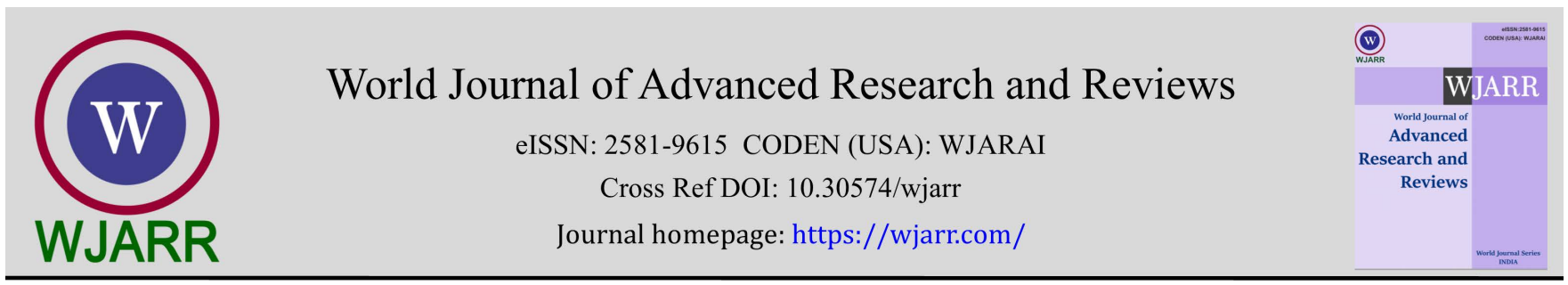

(RESEARCH ARTICLE)

\title{
Elementary Teachers' Attitudes towards Teaching of Tamazight Language in Moroccan Elementary Schools
}

\author{
Mohamed ACHAMRAH * \\ Moulay Ismail University, FLHS, Meknes, Morocco.
}

World Journal of Advanced Research and Reviews, 2022, 13(02), 448-459

Publication history: Received on 01 January 2022; revised on 08 February 2022; accepted on 10 February 2022

Article DOI: https://doi.org/10.30574/wjarr.2022.13.2.0043

\begin{abstract}
Morocco is a multilingual country with rich antiquity. Seemingly, the sociolinguistic status quo in Morocco is marked by its diverse tongues, which are in regular contact. Given this assortment and variety in its linguistic landscape, Morocco opted for teaching Tamazight language in some of its elementary schools since 2003. The current paper brings to the forepart the status of Tamazight in Moroccan elementary schools to know the attitudes of Moroccan elementary teachers towards the teaching of Tamazight in Moroccan Elementary Schools. This study is based on structured interviews targeting Moroccan elementary teachers in different districts of Morocco, using content analysis as the primary method to process the data of this study. In undertaking the aim of this study, this paper addresses the following research questions: (i) what is the status of Tamazight in Moroccan schools? (ii) What is the nature of Moroccan teachers' attitudes towards Tamazight in Moroccan elementary schools? To see whether Moroccan elementary teachers clutch favourable or unfavourable attitudes towards the teaching of Tamazight in Moroccan elementary schools and to what extent those teachers are ready for this change that touches upon the instructive Moroccan context. The findings of this study highlight that Moroccan elementary teachers hold positive and strong attitudes toward Tamazight and its use in Moroccan elementary schools. Participants stated that Tamazight witnessed a period of high-spiritedness and vivacity.
\end{abstract}

Keywords: Mother tongues; Attitudes; Education; The teaching of Tamazight; The linguistic situation in Morocco; Officialization of Tamazight

\section{Introduction}

Morocco is a multilingual society par excellence because of its linguistic marketplace characterised by fertility and constructiveness. To explain more, many local and other foreign languages co-exist, mainly standard Arabic, French, Amazigh, and Moroccan Arabic. Therefore, using these languages bears explicit and obvious political and socio-cultural considerations. Primarily, standard Arabic is an official language used in public institutes, administration and religion. French is a second language that is used in business and elite broadcasting media, whereas Tamazight and colloquial Arabic are associated with streets and homes [9-4].

Like Moroccan Arabic, the Amazigh language has many varieties, each spoken in different provinces in Morocco. To begin with, Tarifit is mainly spoken in the Rife Mountains, mainly in Houceima, Nadour and Imzourn. The second variety is Tamazight, widely spoken in the Atlas Mountains, including Khenifra and Khemissat. The third variety is Tashlhit, principally expressed in the south in the regions of Souss Massa Daràa. More recently, the Tamazight language has been constitutionalised; it has become an official language. Many studies have been conducted to codify and authorise Tamazight language [1-3-6-7]. Yet, the enquiry remains which variety, among the three main varieties of Amazigh language, is to be codified and standardised to be used in the Moroccan elementary schools.

\footnotetext{
${ }^{*}$ Corresponding author: Mohamed ACHAMRAH; E-mail: Mohamedachamrah@gmail.com

Moulay Ismail University, FLHS, Meknes, Morocco.

Copyright $(2022$ Author(s) retain the copyright of this article. This article is published under the terms of the Creative Commons Attribution Liscense 4.0.
} 
The idea of teaching Tamazight in the Moroccan educational system was put forward for the first time on August 20th, 1994, principally when the late King Hassan II offered a speech on the occasion of a national day. At that time, Hassan II declared that teaching and learning Tamazight was compulsory for all Moroccans. Therefore, he created many Amazigh associations to apply all measures said in his royal speech. After that, Mohamed VI, the present Moroccan king, offered a speech on October 17th, 2001, in Ajdir to enact and ratify his father's idea about the issue of Tamazight by setting up the "Dahir" that embraces the creation of the Royal Institute of Amazigh Culture. (IRCAM) [4].

In September 2003, the Moroccan government decided to declare the implementation and the enactment of Tamazight in the Moroccan educational system. In this respect, the Ministry of Education delivered a circular on the operationalisation of the Amazigh language in teaching. Asserting that Tamazight language will gradually be prolonged to all Moroccan schools, namely in all instructive phases of the first grade to the last year of secondary school using its alphabet, Tifinagh.

\section{Problem Statement and Research Questions}

Though there are recurrent studies about language policy in Morocco, most of them were conducted before the constitutional changes made in 2011. Yet, studies examining attitudes towards Tamazight in Moroccan elementary schools are restricted. This study is also unique since it examines Moroccan elementary teacher's attitudes vis-à-vis teaching of Tamazight language in Moroccan elementary schools based on recent changes in the linguistic landscape of Moroccan society. Teaching Tamazight language in Moroccan elementary schools has become a particular focus after the new constitution of 2011 in Morocco. For this reason, research is necessary to understand if Moroccan elementary teachers' attitudes towards teaching Tamazight in Moroccan elementary schools remained the same, or have they changed, regarding language policy and linguistic landscape in the Moroccan community.

\section{Research Questions}

This study investigates Moroccan elementary teachers' attitudes towards Tamazight language in the Moroccan educational system. It mainly tries to see if those elementary teachers hold favourable attitudes towards teaching Tamazight in Moroccan elementary schools. The research enquiries that guide this study are as follows: (i) what is the status of the Amazigh language in the Moroccan elementary schools? (ii) What is the nature of Moroccan elementary teachers' attitudes towards the Amazigh language in the Moroccan elementary schools?

\section{Literature Review}

This section will review the body of literature necessary for this paper. Launched in 2003, Tamazight has declared a language of teaching in 300 elementary schools in different districts of Morocco, advocating Tifinagh script. Students in many Moroccan schools received three hours of instruction in Tamazight per week. The target was to implement Tamazight in all Moroccan schools by 2013, with a further push to train 20,000 teachers in Tamazight instruction [15]. Therefore, more emphasis was given to the Tamazight situation right after the king's speech of 2001 in which the king declared the creation of the Royal Institute of Amazigh Culture IRCAM" (Dahir 2001). Accordingly, the philosophies of the Royal Institute facilitate the dissemination of Tamazight in the instructive Moroccan structures at the national, provincial and local level (Dahir 2001, Article 2). In the same vein, the IRCAMs' main stated objectives are: (i) to write out expressions of Amazigh culture and safeguard them to ensure their diffusion; (ii) to study the writing needed to ease teaching of Amazigh in all Moroccan schools; (iii) to inspire and strengthen the status of Amazigh culture in spaces of communication.

Lately, King Mohamed VI has started a series of legitimate reforms, aiming to assert Tamazight as an official language of the state. Today, Morocco remains the first country to recognise Arabic and Tamazight as co-official languages (Moroccan Const. - Article 5). In Morocco, research on attitudes towards the teaching of Tamazight in the Moroccan educational system displayed that Arabic speaking communities still do not entirely recognise the importance of Tamazight in the Moroccan context. [1-6-7]. Another study by Marley (2004) was conducted among Moroccan students in a non-Tamazight speaking area who exhibited negative attitudes towards the Amazigh language [13]. Still, though attitudes towards Tamazight were largely negative, there was a degree of more attention and care for its institutionalisation to make it an independent language with its own syntactic, semantic, morphological and phonetic norms to be executed in the Moroccan educational context [14].

One more study by Ennaji (1997) argues that native speakers are usually delighted because of their mother tongue [8]. Also, the attitudes of Amazigh or Arab speakers range from neutral to favourable. In his study, Ennaji administered a 
questionnaire to 152 students at the University of Fez to answer the following question: Are you for the idea of teaching the Amazigh language at Moroccan schools? For Ennaji's study findings, 99\% of Amazigh native speakers said Yes, while only $1 \%$ said No, compared to $81 \%$ of Non- native speakers who said Yes, whereas only $19 \%$ said No. In this respect, although Tamazight is traditionally used only by the Amazigh speakers, its revival is due to media coverage of its short news communicated in different varieties of the Amazigh language. In addition to other Amazigh magazines such as Amud and Tifawt as extraordinary samples of better usage of Amazigh language in the media. Henceforward, this has changed the attitudes of both the Amazigh and Arab speakers, the Moroccan society officials, and the more significant presence of activists favouring the Amazigh language, diversity, culture, and identity [10].

\section{Research Methodology}

This section outlines the methodology, instruments and recruitment strategy used in this study. In order to examine Moroccan elementary teacher's attitudes towards Tamazight in Moroccan elementary schools, this study opted for a qualitative approach to analyses attitudes, views, feelings and behaviours of the participants. The data of this paper is based on pre-planned or structured interviews for a group of elementary teachers in different Moroccan districts. These structured interviews examined if Moroccan elementary teachers hold favourable or unfavourable attitudes towards teaching Tamazight in Moroccan elementary schools and to what extent they are ready for this change that will touch upon the Moroccan educational context.

\subsection{Participants}

This study targets Moroccan elementary teachers who grew up in rural and urban milieu. The majority of participants were multilingual, and all of them spoke three to four languages. They were selected based on their willingness to participate in the study and their aptness as Moroccan elementary teachers' community representatives. Participants include male and female elementary teachers with different years of teaching experience. All participants were given assurance of complete anonymity and confidentiality of their responses. Twenty (20) elementary teachers in the structured interview sample were selected based on the snowball sampling technique [2-12]. This method involves building up a sample by identifying a few respondents who match the norms of this study and asking them to recommend other potential participants. Accordingly, making networks was a valuable way to identify and convince participants to participate in this study. This was immensely useful since not all Moroccan schools assign Tamazight in their syllabus. The interviewees' gender and mother tongue are summarised in Table (1). Structured interviews were conducted with a group of male and female elementary teachers, aged between 27 and 54 years and whose years of schooling experiences range between 4 and 26 years. The sample includes respondents with different background information, as reduced in table 2 .

Table 1 Elementary Teachers by Gender and Self-identification of Amazigh ethnicity

\begin{tabular}{|l|l|c|}
\hline \multicolumn{2}{|c|}{ Variable } & Number \\
\hline \multirow{2}{*}{ Gender } & Male & 12 \\
\cline { 2 - 3 } & Female & 08 \\
\hline \multirow{2}{*}{ Self-identification of Amazigh ethnicity } & Yes & 11 \\
\cline { 2 - 3 } & No & 09 \\
\hline
\end{tabular}

\subsection{Structured Interviews}

Structured interviews, also known as standardised interviews, include predetermined questions that the researchers ask each participant in the study to guarantee and ensure that the responses can be gathered to fit the objective of the study [14]. In this context, the reward of applying a structured interview is that it offers consistency in the answers, enabling data comparison. In this study, a set of standard open-ended questions were asked to obtain participants' perceptions, views, attitudes and experiences. Concerning the design of the structured interview, it consists of two parts: The first one is about the background information of the participants and the second part deals with the following themes: (1) the Amazigh language in classrooms, (2) elementary teachers' incentives to teach Tamazight. After gathering the essential data, the following action is to analyse the results to draw conclusions and achieve the research objectives. 
Table 2 Elementary Teachers' Background Information

\begin{tabular}{|c|c|c|c|c|c|c|}
\hline Participants & $\mathbf{G}$ & Age & Level & Name of school & $\begin{array}{l}\text { City /village/ } \\
\text { Countryside }\end{array}$ & Years of Teaching \\
\hline Teacher 01 & M & 40 & $1^{\text {stYear }}$ & Abd Allah ben Yassin & Meknes & 15 years \\
\hline Teacher 02 & $\mathrm{~F}$ & 39 & $3^{\text {rdYear }}$ & Azlagh & Tinajdad & 14 years \\
\hline Teacher 03 & M & 53 & $3^{\text {rdYear }}$ & Tazolt & Amlagou & 26 years \\
\hline Teacher 04 & M & 41 & $3^{\text {rdYear }}$ & Tislit & Tounfit & 11 years \\
\hline Teacher 05 & M & 49 & $1^{\text {st }}$ Year & Aman Nwassif & Ouarzazat & 20 years \\
\hline Teacher 06 & M & 43 & $3^{\text {rdYear }}$ & Sidi Bilal & El Hajeb & 14 years \\
\hline Teacher 07 & M & 33 & $1^{\text {st }}$ Year & Ait Affan & Goulmima & 7 years \\
\hline Teacher 08 & $\mathrm{~F}$ & 37 & $1^{\text {st }}$ Year & Asaka & Irich & 13 years \\
\hline Teacher 09 & M & 50 & $3^{\text {rdYear }}$ & Bno Tachfin & Agadir & 25 years \\
\hline Teacher 10 & M & 35 & $1^{\text {st }}$ Year & Tagadirt & Tinghir & 10 years \\
\hline Teacher 11 & M & 27 & $5^{\text {thYear }}$ & Ait Othman & Ain Leuh & 4 years \\
\hline Teacher 12 & $\mathrm{~F}$ & 30 & $3^{\text {rdYear }}$ & Abou El Kassim & Khnifra & 5 years \\
\hline Teacher 13 & M & 47 & $5^{\text {thYear }}$ & Tarik & Khemisset & 13 years \\
\hline Teacher 14 & M & 31 & $3^{\text {rdYear }}$ & Bouramzin & Timahdit & 5 years \\
\hline Teacher 15 & $\mathrm{~F}$ & 40 & $1^{\text {st }}$ Year & Marz Oulli & Bakrit & 10 years \\
\hline Teacher 16 & $\mathrm{~F}$ & 29 & $3^{\text {rdYear }}$ & Aghbalo & Ifran & 4 years \\
\hline Teacher 17 & $\mathrm{~F}$ & 31 & $5^{\text {thYear }}$ & Ibno Battuta & Midelt & 5 years \\
\hline Teacher 18 & $\mathrm{~F}$ & 38 & $1^{\text {st }}$ Year & Ait Ousrir & Alnif & 10 years \\
\hline Teacher 19 & M & 54 & $3^{\text {rdyear }}$ & AL Atlas & Azrou & 26 years \\
\hline Teacher 20 & $\mathrm{~F}$ & 31 & $1^{\text {st }}$ Year & Ait Nacer & $\mathrm{M}^{\prime}$ rirt & 6 years \\
\hline
\end{tabular}

The interview questions appear as the following:

\subsection{The Interview Questions}

1- Do you agree with the changes in the new constitution of 2011, adding Tamazight as an official language?

2- How do you feel about announcing Amazigh language teaching in elementary schools as the language of instruction?

3- In your belief, what are the expected outcomes of teaching the Amazigh language in Moroccan elementary schools?

4- What can be done to integrate the Tamazight language in Moroccan elementary schools?

5- Do you think it is good to have the Tamazight language in Moroccan elementary schools?

6- Do you think the Tamazight language must be taught in all Moroccan elementary schools?

7- Do you think Tamazight language must be taught to Amazigh students only?

8- Do you think Arabophone students should not learn the Amazigh language?

9- Do you think the teaching of the Tamazight language should not be obligatory?

10- Should Tamazight language be taught only as an optional school subject?

\section{Data Analysis Procedures}

The thematic analysis technique was used to analyse elementary teachers' attitudes towards Tamazight in Moroccan Elementary schools. Thematic analysis is conducted to code data, generate categories and subsequent themes from 
answers given by the respondents [12]. Therefore, the aim of this method is used to understand the phenomenon under study better. The discussions focused on the topic of the study, bringing about meaningful information from respondents. Collected data was assessed and classified according to content, putting the participants' answers into different categories and tabulating the occurrence of recurrent and repeated themes and subthemes. For this reason and to facilitate thematic analysis, the researcher needed to relate and contrast the themes that emerged from participants' responses.

\section{Findings}

It is noted that qualitative data analysis (QDA) embraces an assortment of measures for a thoughtful understanding of the data. In this respect, Gibbs (2007) asserts that qualitative data analysis is based primarily on interpretive philosophy [12]. It is mainly about understanding and interpreting people and situations under investigation by assigning meanings to their words and actions. In the same context, Cohen et al. (2009) argue that researchers should carefully examine the interview texts to identify a set of categories, themes, and subthemes during the transcription process [5].

The data analysis collected for this study revealed many themes and subthemes relevant to Moroccan elementary teachers' attitudes towards Tamazight in Moroccan elementary schools. The data obtained from participants' responses were organised to align with participants' answers. In this respect, the process of classifying several themes necessitates a detailed check of participants' texts to categorise and identify common themes, create categories, ascribe codes and determine patterns that best fit for more interpretation and analysis. The following are themes and subthemes that this study revealed during the interview texts analysis.

\subsection{Theme 1: Standardization of Amazigh Language}

After 17 years since the announcement of Tamazight in the Moroccan education system, today, Tamazight is taught in different Moroccan elementary schools across Moroccan districts. Subsequently, the views regarding the teaching of Tamazight are varied between the applicants of this study. Some participants view Tamazight as a chance for all Moroccan students to get along with their history, culture, and identity. Others think that Tamazight should not be limited to previous aims mentioned above only, but to extend the prospect of Tamazight to become a language of science and technology.

Though the new Moroccan constitution of 2011, essentially Article 5 approves that Tamazight is an official language (See the Moroccan New Constitution of 2011, Article 5), imposing this article remain ambivalent and confusing. To explain more, the standardisation of Tamazight is still a debatable issue because views are divided between all the participants of this study. Some participants stressed the notion of the sociolinguistic authenticity of Tamazight. They stated that Tamazight should dictate how it should be standardised, either by promoting one variety to the status of a standard language or by creating a language based on the common characteristics of different varieties for the Amazigh language to be taught in various districts of Morocco.

\subsection{Theme 2: Teachers' attitudes towards Tamazight in Moroccan elementary schools}

Regarding the attitudes toward Tamazight in Moroccan elementary schools, all the participants share the same views to agree and strongly agree to use Tamazight in Moroccan elementary schools. Participants' answers were more optimistic, asserting that teaching Tamazight in Moroccan schools is a way to preserve Amazigh culture and identity. They also noted that the cultural connection of Tamazight and the strong identity aspect could help keep the language for the possible future, explaining that harmony among Amazigh people seems to be strong even in urban areas. Still, according to some partakers' views in this study, Tamazight, as a school subject, is seldom used in their classrooms. Pointing out that it is used only at home or with friends; besides, only a small number of participants reported using it in some limited schools. Tamazight is seen as a useless language with very slight practical applications in this respect. Hence, according to the obtained information provided by all the participants, the common languages used in their classrooms are standard Arabic and French.

Another worrying issue that this study discovered is the low number of respondents who claimed to read and write Tamazight language using Tifinagh scripts. They pointed out that Tifinagh calligraphy is not widely taught in Moroccan schools. They also argued that most untutored populations tend to come from mainly Amazigh rural areas, so many Amazigh speakers cannot read or write the Amazigh language. Participants' answers about teachers' attitudes towards Tamazight language in the Moroccan elementary schools are summarised in figure (1) 


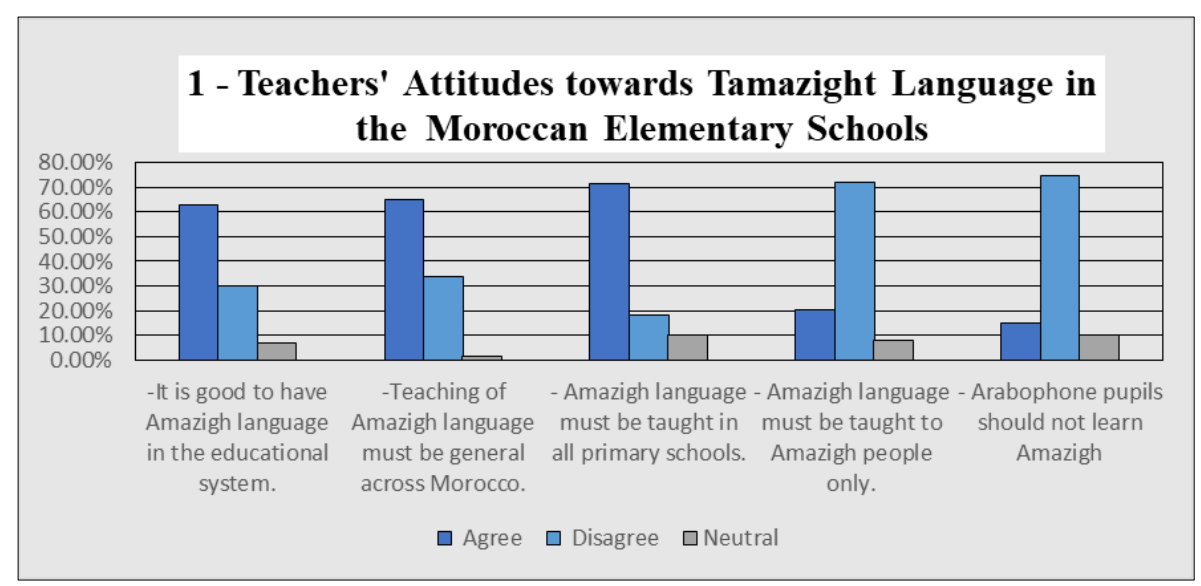

Figure 1 Teachers' Attitudes Towards Tamazight Language in The Moroccan Elementary Schools

In brief, the results provided by the interviewees show agreement and positive attitudes when it comes to the teaching of Tamazight in Moroccan elementary schools. Yet, more attention should be given to Tamazight, the same as other languages.

Most of the informants in this study seem to hold favourable attitudes towards the integration of Tamazight in Moroccan elementary schools. As figure (1) shows, $62.12 \%$ of the participants agree that teaching of Tamazight language must be general across Morocco and that 30\% disagree with that. The respondents also expressed their willingness to introduce Tamazight in all levels of education in the elementary schools; in this respect, $71.79 \%$ of the partakers disagree that only Amazigh pupils must learn Amazigh. 75\% disagree that Arabophone pupils should not learn Amazigh in the same context.

The question: Should Tamazight be obligatory or optional in Moroccan elementary schools? Seeks to see if Moroccan elementary teachers favour using Tamazight as a language of instruction in Moroccan elementary schools. The results show that $(62.82 \%)$ of the respondents agree with this idea to have Tamazight in the educational system. They also want Tamazight to be general across Morocco and not only in restricted places, supporting that learning of Tamazight should not be optional or taught only for the Amazigh students. Other respondents disagree, 30.17\%, while $7.01 \%$ of the applicants were neutral. Figure (1) also suggests that Moroccans are aware of the importance of introducing Tamazight in Moroccan elementary schools. As an illustration and based on the researchers' translation, the following statements provide engaging examples to this worry.

Respondent 19: This is a big decision to introduce Tamazight language into education. This is not our decision; it is the government's decision... We can give our opinions, but we can't change them, and I respect it. But in reality, we would love to have Tamazight in our Moroccan educational system in general and in our elementary schools in particular." (Teacher 19, 54 Years old, male)

In the same vein, the attitudes expressed by the Arabophones participants in this study are reasonably positive. They asserted that the attitudes towards Tamazight in the Moroccan education system necessitate a linguistically diverse country with socio-political and cultural characteristics. They also stressed that Tamazight language should be valorised. Yet other Arabophone participants still finds it hard to admit the reshuffling of language pecking order relations. This can be understood from the following testimonies.

Respondent 02 "First, to be honest, I don't speak Tamazight, but it is not my fault. It is the government's responsibility to be blamed because they should make more... concerts, schools where to study Tamazight and broadcasting stuff on TV. It's also the duty of other people, mainly teachers here. I see that they should keep defensive for their culture, respecting their culture ... because it is a wonderful language, and only the Amazigh people should keep talking about it. It is not our concern, and I mean Tamazight language, because many people do not use it in their daily life except if you go to the rural areas. I think Amazigh people to keep researching that because it is prosperous." Amin, 24 years old, male. (Teacher 02, 39 Years old, female) 


\subsection{Theme 3: Teaching Tamazight in Moroccan Schools as a language of instruction}

Since the creation of the IRCAM institution and the announcement of the Amazigh language in the Moroccan schools, many individuals questioned how this idea would be received and established since they were mindful about the development of already existing languages and their assorted forms in general. In this respect, the Question: How do participants sense about announcing Amazigh language in Moroccan elementary schools as a language of instruction yield diverse answers that can be summarised in figure (2)

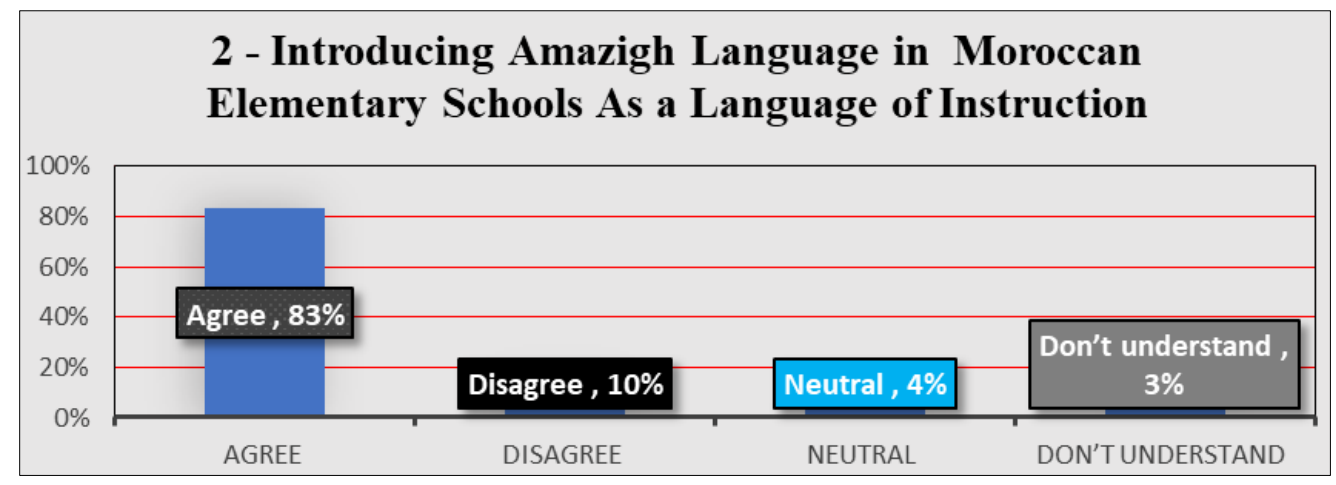

Figure 2 Tamazight in Moroccan Elementary Schools as The Language of Instruction

Figure (2) shows that the respondents' answers are not equally distributed between those who agree to announce Tamazight in Moroccan elementary schools as the language of instruction and those who do not. Throughout the interviewee's thoughts, 83\% agree that the Amazigh language as the language of instruction is necessary for students to fulfil their duties. They believe that introducing Tamazight in Moroccan elementary schools will positively affect students' academic performance. Tamazight is the only way to facilitate students' exposure to knowledge because it is the languages with which students are much familiar, mainly in the rural areas. While only $10 \%$ of the participant disagree that Tamazight should be implemented in Moroccan elementary schools as the language of instruction. Based on the researchers' translation, the following statements illustrate this state of concern:

Respondent 06: "Tamazight is important to be learnt because it is a portion of Moroccan culture and identity" (Teacher 06, 43 years old, male)

Respondent 12: "Of course, Tamazight is a Moroccan legacy it is one of the reasons why our kids I mean our students have to learn it. Thus, it must be taught to all Moroccans... at schools and in every means possible." (Teacher 12, 30 years old, female).

Respondent 18: "As elementary teachers, we have no choice but to teach our students their mother language, which is Tamazight. They should learn to write using Tifinagh writings, and they should speak and use Tamazight in a different context, namely their classrooms." (Teacher 18, 38 years old, female)

\subsection{Theme 4: Incorporating Tamazight in Moroccan Elementary Schools}

Respondents' responses vis-à-vis incorporating Tamazight in Moroccan elementary schools are divided into three categories: The first group includes those who are 'optimistic' with $60 \%$. The second group involves 'pessimistic' with $31 \%$ teaching Tamazight language in Moroccan elementary schools. The third group are those who are 'neutral' with $9 \%$. The following figure (3) digests the respondents' views about incorporating Tamazight in Moroccan elementary schools.

As an illustration, the following statements provide an interesting explanation of this dilemma.

Respondent 10: "Including or incorporating Tamazight in Moroccan elementary schools will never harm the standard Arabic. I think the Tamazight should be promoted more in Moroccan elementary schools, the same as Arabic. I think also Tamazight must be the language of education in general and in elementary schools in particular". (Teacher 10, 35 Years old, male)

Respondent16: "I think it is the job of the state to take care of Tamazight and take the decision of including Tamazight in all Moroccan elementary schools without exceptions. However, the incorporation involves many steps: standardisation first, 
I mean the officialisation of Tamazight, then its implementation. Also, some Moroccans who are biased need to change their negative attitudes towards Tamazight" (Teacher 16, 20 Years old, female).

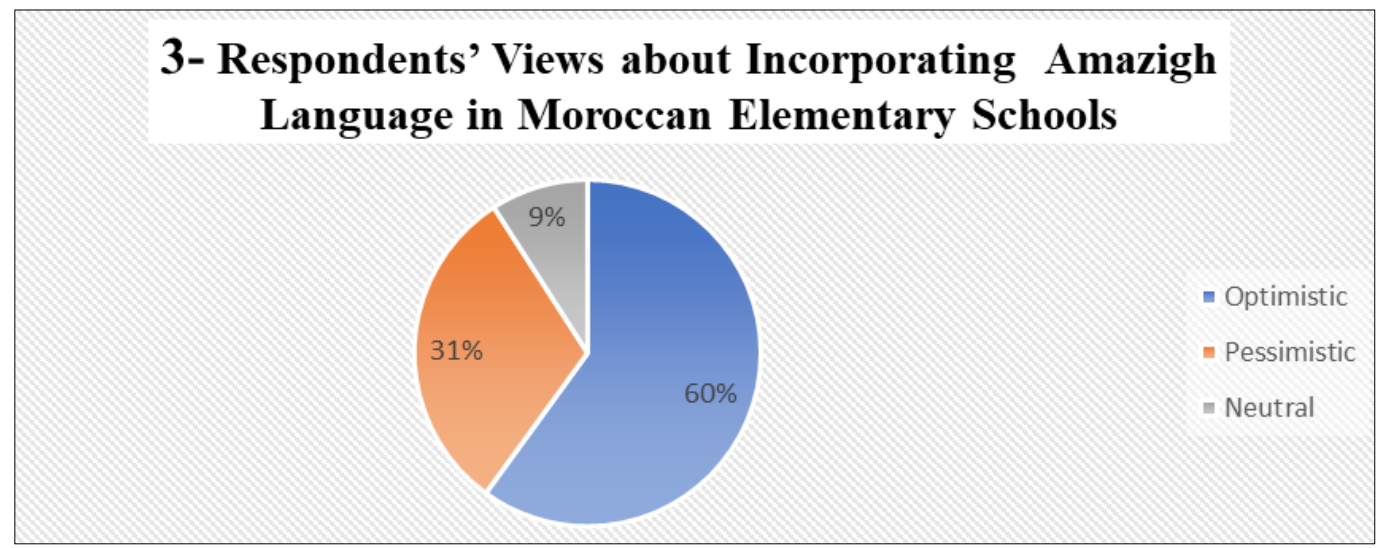

Figure 3 Respondents' views about incorporating Tamazight in Moroccan elementary schools

\subsection{Theme 6: Using Tamazight as a language of instruction in Moroccan elementary schools}

The attempts to know about Moroccan elementary teachers' attitudes towards the use of Tamazight as a language of instruction the same like other languages such as standard Arabic and French revealed that the majority of the participants opted for 'Agree' with a percentage of 45\%, followed by those who disagree 18\%, Strongly Disagree (11\%), Neutral (5\%), and Strongly Agree (21\%). Obviously, the results are significant when one moves from 'Agree' to 'Disagree' and 'Strongly Agree'. Figure (4) suggests respondents' responses about using Tamazight as a language of instruction in Moroccan elementary schools.

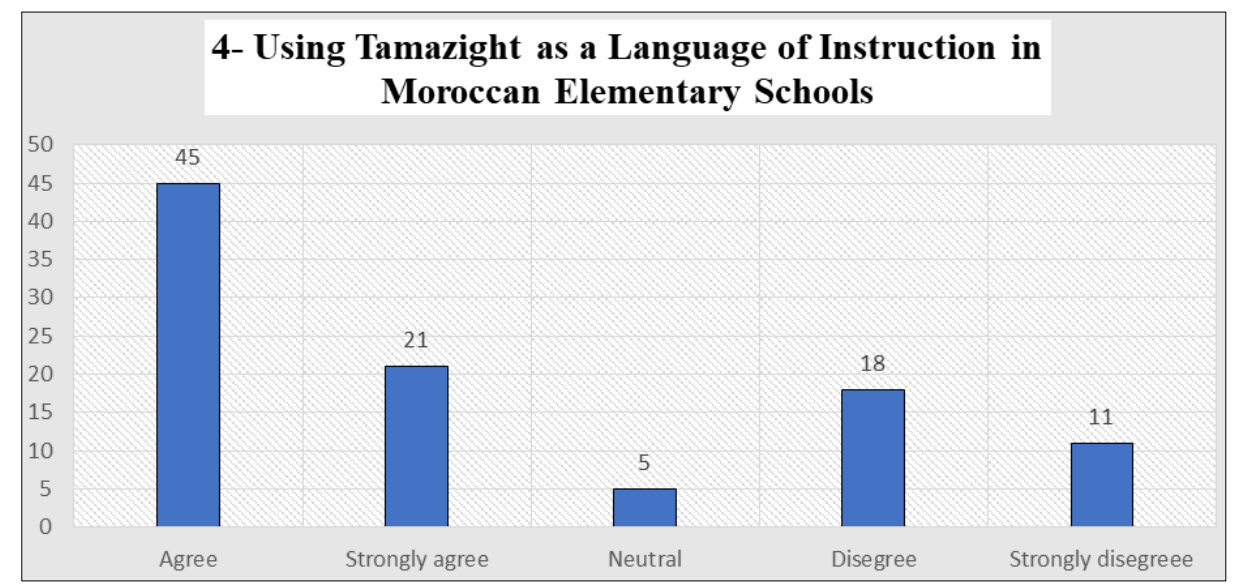

Figure 4 Using Tamazight as a language of instruction in Moroccan elementary schools

This also means that Moroccan elementary teachers welcome Tamazight language to be incorporated to be the language of instruction, mainly in Moroccan elementary schools and that the presence of Amazigh language in their educational system is inescapable, as it is shown in the following statements

Respondent 15: "Tamazight is something that is Moroccan. All Moroccan people should be proud of that. Yes, Tamazight should be the language most elementary teachers have to use. I think the same as other teachers, it is a shame to use other languages and forget about our mother tongue. People should stop that. Tamazight is going to be better if they make it better. It is not only for those who want to but instead for all. As we said, this language must not be an option in schools; instead, it should be compulsory, but how? I think there must be some language centres or something like that. Unfortunately, the government is not taking measures on such issues.". (Teacher 15, 40 Years old, female)

Respondent 13: "As elementary teachers in Moroccan schools, if we deny the Tamazight. We deny many people, and we deny a whole culture. Yes, it is true. I have friends who are teaching in different places. They all agree to use Tamazight in all Moroccan elementary schools without exceptions. Yes, because Tamazight is a language that most people use in 
Morocco. it should be implemented in all Levels of Moroccan elementary schools because it refers to our identity and we cannot deny that, yes Tamazight should be taught, and it should be implemented in Moroccan schools" (Teacher 13, 47 Years old, female)

\subsection{Theme 7: Moroccan government should pay more attention to the development of Tamazight}

To see if the Moroccan government should pay more attention to the development of the Tamazight language, the same as other languages, is essential in this study. Hence, the results demonstrated that (23\%) of the respondents strongly agree that the Moroccan government should consider improving the Amazigh language, followed by (39\%) of participants who agree. In contrast, others either disagree or strongly disagree, their percentages being (18\%), (17\%) respectively and (3\%) are neutral. Figure (5) also suggests that the Moroccan government should pay more attention to the development of the Amazigh language in elementary schools.

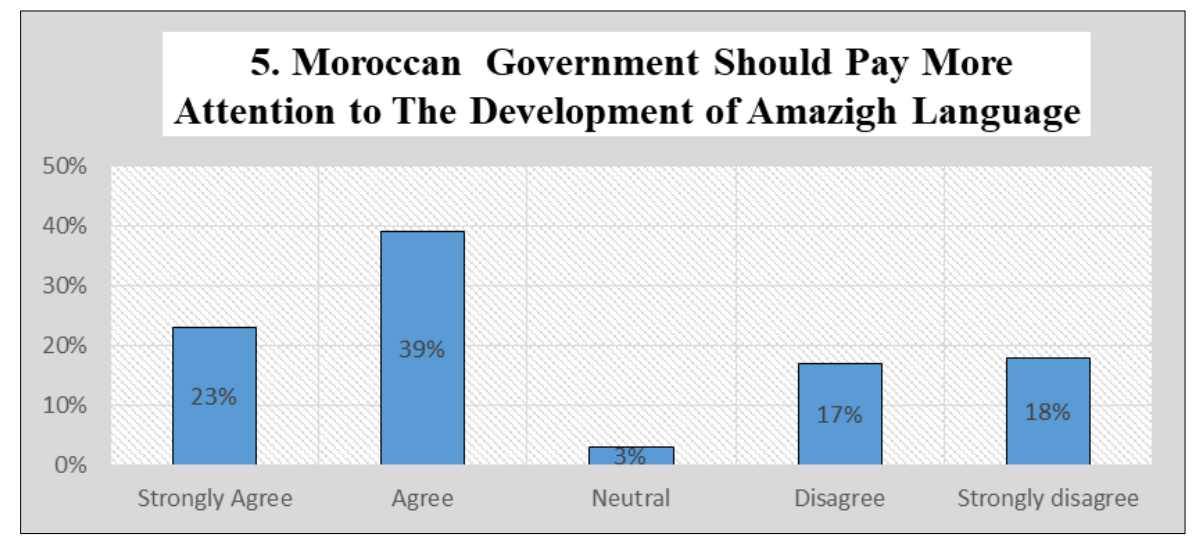

Figure 5 Moroccan government and the development of the Amazigh language

\subsection{Theme 8: Arabization denigrates the status of the Amazigh language in Morocco}

As revealed in figure (6) below, the respondents' degree of disagreement is higher. In this respect, $47 \%$ and $23 \%$ of the respondents disagree and strongly disagree that the Arabic language denigrates the status of the Amazigh language in Morocco. While $10 \%$ of the respondents opted for 'strongly agree' with the idea that standard Arabic denigrates the status of the Amazigh language in Morocco. Figure (6) suggests respondents' responses if standard Arabic offends the status of the Amazigh language in Morocco.

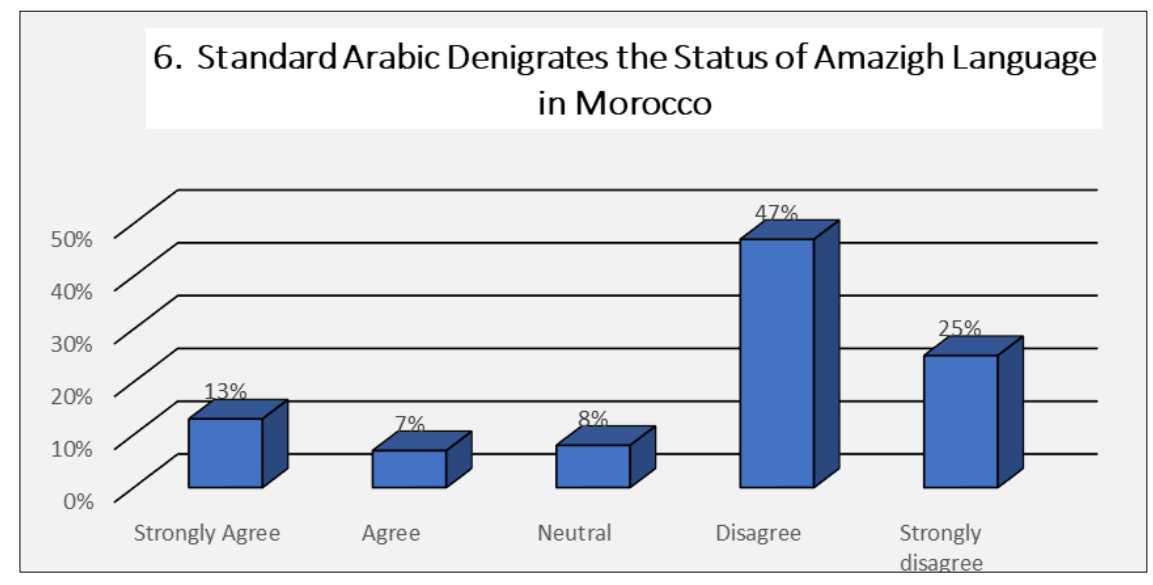

Figure 6 Respondents' responses if standard Arabic vis-à-vis the status of the Amazigh language in Morocco

Figure (6) infers that Moroccan elementary teacher believe that Arabization does not affect the status of Tamazight as their mother tongues. It is also evident that attitudes determine the position of the language and its safeguarding, therefore its renaissance. As pointed out, some people have a negative attitude towards Tamazight language. A question of awareness at this point is how to adjust this attitude? One way is to use the language the same as other languages since the success of any language policy depends significantly on the state's efforts in executing a good image or status about this language. Thus, for a language and its culture to be well-looked-after, it must be diffused to the next 
generations. One way to accomplish this is using it in the educational system because of its active and forceful role in developing the language.

\section{Discussion of the Findings}

The linguistic situation in Morocco is naturally thorny. Today, Moroccan individuals' verbal repertoire includes Arabic (all the forms), Tamazight (all varieties), French, and other foreign languages. Tamazight-speakers are spread through the whole district of North Africa. It has also been documented as an official language, but its standardisation and incorporation into the Moroccan educational system face many hindrances. The present section discusses the status of Tamazight language and the extent to which Tamazight is implemented in the Moroccan educational system in general and in Moroccan elementary schools in particular. Besides, many conclusions will be drawn, and recommendations will be formulated to improve Tamazight language learning and teaching in Moroccan elementary schools.

In this paper, Moroccan elementary teachers were offered structured interviews to describe their experiences and state whether Tamazight language is valued as teaching in the Moroccan elementary schools. The focal objective is to determine whether teachers' attitudes towards Tamazight have changed or not; and whether the Amazigh language has succeeded in gaining some ground on the language policy, mainly in the Moroccan elementary schools. In this study, respondents' attitudes towards the Amazigh language in Moroccan elementary schools are characterised by some degree of inconsistency and variation, in the sense that some respondents consider Tamazight language their mother tongue within which they identify themselves and their culture. Hence, it should be protected and used as the language of education. For them, Tamazight should be used in everyday communication with the impression that Tamazight is rich if it is to be used in formal spheres, particularly in educational settings. According to the data provided by the respondents, the common languages used in their classes are standard Arabic and French as languages of interactions inside the classrooms. In contrast, Tamazight is used outside the classrooms, at home and in the street with their friends. Many participants stated that they use Tamazight when conversing with their students in non-class settings.

The results of this study displayed agreement among the participants regarding the teaching of Tamazight in Moroccan elementary schools. It emphasises their willingness and their positive attitudes towards it. In the same respect, many participants asserted that there had been a positive change in attitudes towards Tamazight in recent years and that teaching it is one of the reasons behind this shift. Other interviewees in this study state that teaching or speaking Tamazight is harshly despised and hated by the non-speakers of this language and sometimes by its speakers. Concerning the teaching of Amazigh, $50 \%$ of the informants have a positive attitude towards teaching it in Moroccan elementary schools, while only $10 \%$ are against teaching Tamazight in Moroccan elementary schools, and $5 \%$ of the participants instead adopt a neutral position. The majority of the informants who have a positive attitude towards the teaching of Tamazight argue that the Amazigh language is a Moroccan legacy. Therefore, the Tamazight language teaching shall help preserve this legacy. They also claim that the teaching of Tamazight is a kind of get-together and reconsideration for Amazigh people who had been marginalised and devalued for a long time. On the other hand, participants against teaching Tamazight in Moroccan elementary schools think that this will influence the status of standard Arabic, confessing that if Tamazight has to be taught in Moroccan elementary schools, it should be conducted only to those who want it. They do not want it to be generalised. They also think that Tamazight should be optional and not compulsory for all students.

The results regarding denigrating the status of the Amazigh language in Morocco show that (47\%) and (23\%) of informants strongly disagree and disagree, respectively with this claim. They also asserted positive attitudes towards Tamazight as a vital constituent of the Moroccan heritage. Therefore, its usage in the schoolrooms as a language of the first residents of Morocco will help preserve and transmit its culture to the next generations. At this point, and in the light of the discussion of the findings, we may claim that teachers' attitudes towards Tamazight language, most of them, seemed rather more positive, unlike what has been said in the previous studies [1-3]. Accordingly, in this study, participants' attitudes towards Tamazight seem to have improved due to the changes that the status of this language has undergone over the last decades, thanks to its declaration in the Moroccan educational system since 2003, the establishment of a Royal institute (IRCAM) and the king's official support for this language, mainly the text of the constitution which states: "Likewise, Tamazight creates an official language of the State, being the common patrimony of all Moroccans without exception" (Article 5).

The attitudes expressed by the Arabophone elementary teachers who participated in the study are also soberly positive. Their attitudes towards implementing Tamazight language in the education system entail sociopolitical and cultural aspects. Still, some people involved in the change find it difficult to accept the reshuffling of language hierarchies besides the balance in power relations among languages. In this context, respondents expressed their positive attitudes towards the integration of Tamazight in the educational system as a language of instruction. They stated that classrooms are 
sitting rooms where this language can be valorised. This could help modify the power relations that have governed the two ethnolinguistic groups throughout history in Morocco.

Based on the analysis and the outcomes obtained from this study's interviews, responses to the question: If the government should do more to promote Tamazight language the same as other languages was interesting mainly due to the participants' positive views. This study demonstrates that $(23 \%)$ of the respondents strongly agree that the Moroccan government should take different measures and practices to improve Tamazight, followed by (39\%) of participants who agree. This is somewhat contrary to negative responses recorded in previous studies by [11- 14]. Despite changes in language policy, the survival of the Amazigh language among Moroccan elementary teachers is uncertain. Some participants view languages as communicative apparatuses to help them climb the social ranking. In this regard and based on the findings of this study, some interviewees see Tamazight as a useless language, stating that adopting it as a medium of instruction could hinder students' progress in other more essential languages such as French and English. In their words, the adoption of the Amazigh language in Moroccan elementary schools constitutes a significant burden to pursuing one learning process. These partakers displayed pessimism towards Tamazight. They also reported to have opposed its enactment and implementation in their classrooms; however, they fail to recall the cultural linking of Tamazight and the vital identity aspect of the language.

In brief, researchers in this study tried to explore attitudes and perceptions of Moroccan elementary teachers toward Tamazight and how they see its usage in Moroccan elementary schools. The results revealed that most participants' attitudes ranged from positive to neutral. Yet, most participants hold strong positive feelings toward Tamazight and its usage in Moroccan elementary schools. Participants' favourable attitudes toward the Amazigh language are highly linked to preserving their legacy. This study also revealed that Moroccan elementary teachers are conscious of the change in language policy and the linguistic landscape that is presently changing. However, the only statement that produced ultimately neutral responses by the study applicants was Tamazight becoming a mandatory school subject in Moroccan elementary schools.

\section{Limitations}

This study studied Moroccan elementary teachers' attitudes towards the Amazigh language in the Moroccan elementary schools in urban and rural areas. It also investigated the potential costs of specific shifts in language policy within said community. Throughout this study, various limitations regarding the sample, data collection, and methodology need to be outlined and discussed. First, the sample size comprised in this study was only 20 Moroccan elementary teachers, which is too low as true representatives of the Moroccan elementary teachers' community. Another limitation regarding the sample is related to the location and background of the participants. Most of the applicants were born and raised in rural areas. In order to legalise the findings of this study, further research should look into possible differences in attitudes between a much larger sample and more interview question items to examine the results found in this study. Another limitation concerning this study is that participants were hesitant in answering questions due to the delicate nature of the topic.

\section{Recommendations}

Based on the above discussion and in the light of the conclusions drawn from the data analysis, some recommendations can be voiced for Moroccan elementary teachers to use Tamazight in their classrooms. In this respect, there must be an instant implementation of the official Amazigh language at all grade levels to extend the spreading use of Tamazight in Moroccan elementary schools, Moroccan administrations, and other public institutions.

Accordingly, to improve the Tamazight teaching and learning process, we recommend the following measures that should be taken into thought by the concerned authorities. First, it is essential to re-examine the linguistic system of the Tamazight language. Second, creating the Academy of Tamazight which can be helpful to solve Tamazight problems. Besides, partnerships with Moroccan universities need to be strengthened. Hence, operative coordination between teachers of different levels, on the one hand, and university level formation, on the other hand, is much needed. Finally, more effort needs to be exerted to improve the Amazigh language to teach and learn the language for communicative competence.

\section{Conclusion}

The present study investigated the attitudes of Moroccan elementary teachers towards Tamazight in Moroccan elementary schools. In this study, although many Moroccan elementary teachers agree that Tamazight language can facilitate learning, others see it less likely to be adopted as an official language of instruction in Moroccan elementary 
schools. Additionally, Tamazight language is still viewed as a lower or substandard variety that is not worthy of academic study, much less being implemented as a language of instruction across the country. Therefore, the lack of political cohesiveness regarding Tamazight language instruction and the dominance of other foreign languages such as English and French have also reserved the role of academics in the decision-making process. Hence, the successful implementation of Tamazight language as a language of instruction in Morocco requires a shift in power dynamics among political and academic agents. In this respect, academics should embark more on the standardization of Tamazight language and create effective ways to increase their corpus and status in society. These measures will probably change Moroccan elementary teachers and other people's attitudes towards Tamazight language to treat it as a language that can play an essential or pivotal role in the national educational system.

\section{Compliance with ethical standards}

\section{Acknowledgments}

The author is grateful to all those who have contributed and helped in completing this article

\section{Disclosure of conflict of interest}

The author has no conflicts of interest to declare. The author alone is responsible for the content and writing of the paper

\section{Statement of informed consent}

Informed approval was obtained from all participants involved in the study.

\section{References}

[1] Afkir M. Linguistic diversity and cultural plurality in contemporary Morocco: Official and unofficial discourse. Paper presented at the conference: Les changements linguistiques au Maroc: Bilan et évaluation. Ibn Zohr University, Agadir, Morocco. 2011.

[2] Bhattacherjee A. Social science research: Principles, methods, and practices. USF Tampa Bay Open Access Textbooks Collection. 2012.

[3] Boukhris F. et al. La nouvelle grammaire de l'amazighe, Rabat, Publication de l'Institut Royale de la Culture Amazighe, El Maârif $\mathrm{Al}$ jadida. 2008.

[4] Boukous A. Language policy, identity and education in Morocco. Languages and Linguistics. $2001 ; 8$ : 17-27.

[5] Cohen L, Manion L, Morrison K. Research Methods in Education (6th edition). London. Routledge. 2009.

[6] El kirat El Allame, Y. Issues in the representation of Amazigh language and identity. In North Africa. Langues et Littératures. 2009; 19: 179-196.

[7] El Kirat EY, Bennis S. L'enseignement de la langue Amazighe entre dialectologie et standardization, déperdition, maintien et/ou revitalisation. Langues et Littératures. 2010; 20: 13-41.

[8] Ennaji M. The sociology of Berber: Change and continuity. International Journal of the Sociology of Language. 1997; 23-40.

[9] Ennaji M. Multilingualism, Cultural Identity, and Education in Morocco. New York: Springer. 2005.

[10] Errihani M. Language attitudes and language use in Morocco: effects of attitudes on 'Berber language policy'. The Journal of North African Studies. December 2008; 13(4): 411-428.

[11] Gay LR, Mills GE, Airasian P. Educational research: Competencies for analysis and application. Upper Saddle River, NJ: Pearson. 2012.

[12] Gibbs G. Analysing qualitative data. London, UK: Sage. 2007.

[13] Marley D. Language Attitudes in Morocco Following Recent Changes in Language Policy. Language Policy. 2004; 3, 25-46.

[14] Kumar R. Research Methodology. A Step-By-Step Guide for Beginners, SAGE Publication, third ed. 2011.

[15] Tomastik K. "Language Policy in the Kingdom of Morocco: Arabic, Tamazight, and French in Interaction." The Annual of Language \& Politics and Politics of Identity. 2010; 4: 101-116. 